\title{
Desempenho dos alunos de Ciências Contábeis na prova Enade/2012: uma aplicação da Teoria da Reposta ao Item
}

\section{Resumo}

Este estudo teve como objetivo mensurar o desempenho (proficiência) dos estudantes de Ciências Contábeis no Enade por meio da Teoria da Resposta ao Item (TRI). A mensuração do desempenho dos estudantes foi realizada, utilizando-se o modelo logístico de três parâmetros (ML3P), com dados extraídos do site do Instituto Nacional de Estudos e Pesquisas Educacionais Anísio Teixeira (Inep) relativos à prova Enade/2012, contemplando 47.098 estudantes. A escala elaborada permitiu discriminar os estudantes em três níveis de desempenho. Observou-se que estudantes situados no Nível 1 têm domínios relacionados a leitura e interpretação de textos e raciocínio quantitativo. À medida que passa para o Nível 2, o estudante, além dos domínios do nível anterior, deve apresentar raciocínio lógico e visões sistêmica e holística. No Nível 3, complementarmente aos domínios exigidos nos níveis 1 e 2, devem apresentar conhecimento interdisciplinar entre os conteúdos contábeis, capacidade crítico-analítica, e aplicação prática dos conteúdos dominados. Os resultados apontaram também que os itens contidos na prova Enade representaram um alto grau de dificuldade para o grupo que realizou a prova. Independente das características analisadas os estudantes, em geral, apresentaram proficiências muito baixas. Esse resultado sugere que são necessárias ações das IES e políticas públicas capazes de contribuir para a melhoria do desempenho apresentado pelos estudantes.

Palavras-chave: Desempenho de estudantes; Proficiência; Enade; Teoria da Resposta ao Item.

\section{Raphael Vinicius Weigert \\ Camargo \\ Mestre e doutorando em Contabilidade pela Universidade Federal de Santa Catarina (UFSC) e Professor da Universidade Estadual do Paraná (Unespar). Contato: Rua Comendador Correa Junior, 117. Centro. Paranaguá-PR. CEP.: 83203-560. \\ E-mail: raphael.camargo@unespar.edu.br}

\section{Rita de Cássia Correa Pepinelli Camargo}

Mestre e doutoranda em Contabilidade pela Universidade Federal de Santa Catarina (UFSC) e Contato: Campus Universitário Trindade, Departamento de Ciências Contábeis, Bloco C - sala 215. Bairro: Trindade. Florianópolis-SC. CEP.: 88040-970. E-mail: rita.camargo@ufsc.br

\section{Dalton Francisco de Andrade} $\mathrm{PhD}$ in Biostatistics pela University of North Carolina at Chapel Hill, NC - USA e Professor Titular da Universidade Federal de Santa Catarina (UFSC). Contato: Campus Universitário Trindade, Centro Tecnológico, Departamento de Informática e Estatística, sala 509. Bairro: Trindade. Florianópolis-SC. CEP.: 88040-900.

E-mail: dalton.andrade@ufsc.br

\section{Antonio Cezar Bornia}

Doutor em Engenharia de Produção pela Universidade Federal de Santa Catarina (UFSC) e Professor Titular da Universidade Federal de Santa Catarina (UFSC). Contato: Campus Universitário Trindade, Centro Tecnológico, Departamento de Engenharia de Produção e Sistemas, CP 476. Bairro Trindade. Florianópolis-SC. CEP.: 88040-900. E-mail: cezar.bornia@ufsc.br 


\section{Introdução}

A educação pode ser entendida como um bem econômico escasso, que depende de escolhas e renúncias de recursos, individuais ou coletivas (Waltenberg, 2006). De acordo com Cunha, Cornachione Junior e Martins (2010), estudos empíricos apontam que a importância da educação e seus reflexos são maiores em países em desenvolvimento, se comparados com os países desenvolvidos. O estabelecimento e manutenção de políticas públicas relacionadas a sistemas de educação financeira, accountability educacional e integração educacional dependem, essencialmente, do acompanhamento da situação em que se encontra a educação ofertada, realizado, normalmente, por meio de avaliações (Hanushek, 1979).

Conforme Hanushek (1979), testes de avaliação de conhecimento educacional são utilizados como forma de medir o resultado do processo de produção educacional. Para Primi, Hutz e Silva (2011, p. 271), "em sociedades democráticas, tais avaliações servem como instrumentos de prestação de contas (accountability), utilizados para examinar se as organizações, às quais são determinados alguns papéis, têm cumprido suas obrigações".

Como um bem econômico escasso, um parâmetro para aferição de seu estágio atual é a qualidade da educação, parâmetro esse que sustenta a avaliação da efetividade do ensino. No Brasil, o ensino superior é avaliado periodicamente por órgãos de acompanhamento da educação subordinados ao Ministério da Educação (MEC). No caso do ensino em nível de graduação, esse acompanhamento é realizado pelo Sistema Nacional de Avaliação da Educação Superior (Sinaes), que adota o Exame Nacional de Desempenho dos Estudantes (Enade), criado em 2004, como instrumento para avaliação do desempenho de estudantes em cursos de ensino superior em relação aos conteúdos programáticos, e suas habilidades (Instituto Nacional de Estudos e Pesquisas Educacionais Anísio Teixeira [Inep], 2014). Além disso, "as diretrizes para a elaboração da prova da área de Ciências Contábeis estão definidas na Portaria Inep n. ${ }^{\circ} 202$, de 22 de junho de 2012" (Inep, 2014, p. 6). Cabe salientar que, além do objetivo estabelecido pelo Sinaes de avaliar o desempenho dos estudantes, a prova do Enade também é adotada para avaliar o desempenho das instituições de ensino na transmissão de conhecimentos para a formação do aluno em relação à aderência aos componentes curriculares dos cursos baseados em uma Diretriz Curricular Nacional.

Esse exame tem sido utilizado, para além das finalidades estabelecidas pelo Sinaes, como fonte de mensuração do desempenho de estudantes do ensino superior em pesquisas científicas. Essas pesquisas, normalmente realizadas no âmbito de áreas específicas de conhecimento, como Psicologia, Pedagogia, Administração, entre outras áreas, buscam conhecer a situação em que se encontra o ensino dessas respectivas áreas. Essas avaliações, realizadas a partir de mensurações de desempenho, são efetuadas com vistas à busca de ações para melhoria da educação e compreensão de fatores (determinantes) relacionados ao maior (ou menor) desempenho acadêmico, aferido com base nas provas do exame.

A partir da literatura científica que apresenta mensurações do desempenho acadêmico de estudantes de curso superior, pode-se perceber a predominância de estudos que se utilizam da Teoria Clássica dos Testes (TCT) para aferição do conhecimento demonstrado pelos estudantes. Com base nessas mensurações, é que são avaliadas as necessidades de melhoria da educação oferecida, elaboradas sugestões de aprimoramento do ensino e compreendidos os fatores que auxiliem na explicação das causas pelas quais o desempenho tende a ser maior ou menor. No entanto, por meio da análise clássica, esse levantamento pode não expressar a realidade do desempenho acadêmico, por não considerar as especificidades de cada item que compõe a avaliação.

Nas áreas de Psicologia e Pedagogia, respectivamente, os estudos de Primi et al. (2011) e Lopes e Vendramini (2015) empregaram o uso da Teoria da Resposta ao Item (TRI) como forma alternativa de mensuração do desempenho (proficiência) de alunos nas provas do Enade. Observa-se nesses estudos que a avaliação efetuada com base na TRI apresenta resultados com maior grau de detalhamento da proficiência dos indivíduos avaliados, oferecendo inclusive informações acerca de qual o conhecimento especificamente dominado pelos indivíduos, em que tanto o item como o respondente são colocados em uma mesma escala de mensuração. Assim, entre outras observações possíveis, pode-se mencionar a comparação da dificuldade da prova em relação ao conhecimento (proficiência) do grupo de estudantes. 
Diferentemente da TCT, a TRI possibilita a aferição do conhecimento (proficiência) dos estudantes, de acordo com a complexidade do conteúdo que compõe cada questão do exame. Com base nessa mensuração, é possível identificar a proficiência efetivamente demonstrada pelo estudante, uma vez que não considera apenas a quantidade de itens corretamente respondidos. Sob essa perspectiva, é possível realizar a diferenciação entre indivíduos, de modo que diferentes alunos, que tenham acertado uma mesma quantidade de questões (itens), com graus diferentes de dificuldade, tenham medidas de proficiência diferentes.

Este estudo busca contribuir com o ensino de Ciências Contábeis no Brasil, por apresentar uma mensuração alternativa do desempenho dos estudantes da área por meio da TRI. Assim, o presente estudo tem como objetivo mensurar o desempenho (proficiência) dos estudantes de Ciências Contábeis no Enade por meio da TRI.

Busca-se, com o presente estudo, modelar a probabilidade de acerto das questões (itens) que compõem a prova, considerando-se a proficiência do estudante a partir da dificuldade e capacidade de discriminação dos itens e da probabilidade de acerto casual. Por permitir uma avaliação do conhecimento efetivamente dominado pelo estudante em cada item, esta iniciativa possibilita intervenções e ações pontuais de correção no processo de ensino-aprendizagem, de modo a identificar lacunas que compreendam possíveis deficiências de aprendizagem.

Pela consideração da educação como um recurso escasso, sua importância em países subdesenvolvidos e a busca pelo desenvolvimento de políticas públicas relacionadas à educação, a problemática do presente estudo é norteada pela Teoria Econômica da Educação. Este trabalho busca avaliar a situação do ensino superior na área de Ciências Contábeis, por meio do desempenho de estudantes, que correspondem a um dos produtos finais da educação, enquanto egressos. Isso porque é necessário avaliar e compreender se o recurso "educação" é gerido de modo a proporcionar benefícios privados e sociais.

Espera-se, portanto, contribuir com a área de educação em Contabilidade com a busca de instrumentos alternativos para aferição da situação atual do ensino superior em Ciências Contábeis no Brasil, consubstanciada na avaliação do desempenho acadêmico dos estudantes (proficiência), de modo a avaliar, detalhadamente, a situação encontrada em cada tipo de conhecimento que integra os componentes curriculares dos cursos de ensino superior em Ciências Contábeis.

O artigo está dividido em cinco seções. Na próxima seção é apresentado o referencial teórico, que engloba a Teoria Econômica da Educação, Teoria da Resposta ao Item e estudos anteriores relacionados ao tema do artigo; a terceira seção expõe os procedimentos metodológicos seguidos na pesquisa; a quarta seção apresenta os resultados do estudo, contemplando a estimação dos parâmetros do modelo adotado, a mensuração da proficiência dos estudantes e a escala de proficiência construída. Na última seção, é exposta a conclusão da pesquisa e sugestões para futuros estudos.

\section{Referencial Teórico}

\subsection{Teoria Econômica da Educação - Capital Humano}

Blaug (1992) classifica as pesquisas baseadas na Teoria da Economia da Educação em dois grandes campos. O primeiro está relacionado à análise do valor econômico da educação e o segundo investiga os aspectos econômicos dos sistemas educacionais. Estudos ligados à primeira linha concluíram que o crescimento econômico de um país ou região possui relação estreita com nível de educação dos habitantes (Waltenberg, 2006). A vertente teórica do capital humano está inserida nesse primeiro campo da Teoria Econômica da Educação.

A Teoria do Capital Humano visa essencialmente compreender e explicar os reflexos da educação sobre o valor do capital humano das pessoas. Nessa corrente, o ganho de conhecimentos e habilidades provoca um acréscimo ao valor do capital humano dos indivíduos, com reflexos em empregabilidade, produtividade e rendimento potencial (Cunha et al., 2010). Sob essa perspectiva, a educação pode ser considerada um bem econômico, com problemas de escassez e dependente de escolhas e renúncias em termos de recursos, tanto individuais, como coletivas (Waltenberg, 2006). 
Essa ideia deriva das visões de Schultz (1960), considerado um dos precursores da Teoria do Capital Humano. Para o autor, a educação pode ser tratada como uma forma de investimento no ser humano e que passa a agregar valor ao indivíduo que a recebe. Nessa concepção, acréscimos de rendimento e produtividade são decorrentes do aumento do capital humano. O capital humano, enquanto investimento no ser humano, é composto de dois tipos de recursos. O primeiro diz respeito aos recursos investidos pelas instituições de ensino, e o segundo, aos investimentos efetuados pelos próprios indivíduos, na forma de renúncias de ganhos enquanto estudantes. Este último recurso foi observado empiricamente por Schultz (1960) como a parte mais expressiva dos custos incorridos na formação do estudante.

Posteriormente, Becker (1962) contribuiu para a expansão da Teoria do Capital Humano, por meio de estudos empíricos das consequências do ganho desse capital sobre questões como bem-estar e riqueza. Para Waltenberg (2006), os resultados encontrados nos estudos realizados nessa área ainda carecem de uma relação quantitativa direta entre crescimento econômico e educação. Não se tem a definição de um nível ótimo de educação para um país. Não existe consenso de um nível mínimo de educação que faça com que um país atinja uma condição de crescimento acelerado, tampouco são conhecidos os prazos de maturação e depreciação do capital humano. Rasera (1999) destaca que a educação possui um problema relacionado a sua forma de mensuração, o que torna difícil mensurar uma relação razoável entre crescimento econômico e investimento em capital humano. Assim, uma das poucas conclusões possíveis é de que a educação fomenta o crescimento de um país, contudo, sem precisar o grau de relacionamento entre essas duas variáveis.

A mensuração e a compreensão dos determinantes do desempenho educacional são importantes para o desenvolvimento de políticas tais como de accountability educacional, de sistemas de educação financeira e de integração educacional. A maior parte dos estudos nessa linha utiliza como medida de desempenho as saídas padronizadas obtidas das notas obtidas nas provas (Hanushek, 1979). No entanto, o que se percebe nos estudos dessa natureza é a predominância da mensuração do desempenho educacional com base na Teoria Clássica dos Testes (TCT). Essa forma de mensuração possui algumas fragilidades, sobretudo no que tange à avaliação do desempenho em função das particularidades de cada item que compõe o instrumento de avaliação, especificamente, as provas realizadas por estudantes.

Estudos como os de Primi et al. (2011) e Lopes e Vendramini (2015) empregaram o uso da Teoria da Resposta ao Item (TRI) como forma alternativa de mensuração do desempenho (proficiência) de alunos nas provas do Enade. A partir da Teoria da Resposta ao Item (TRI), apresentada com maiores detalhes nos tópicos seguintes deste estudo, é possível a obtenção de uma mensuração capaz de avaliar o desempenho de alunos, de modo a medir e diferenciar o conhecimento apresentado pelo aluno na prova. Nesse sentido, a TRI pode contribuir com a corrente do capital humano no desenvolvimento da Teoria Econômica da Educação.

Esses estudos têm como contribuição o provimento de um feedback quanto à qualidade da educação oferecida à população. Isso porque há a necessidade de uma maior efetividade no ensino, sobretudo por seus efeitos em diferentes setores e camadas da organização sociopolítico-econômica de um país (Lopes \& Vendramini, 2015). 


\subsection{Teoria da Resposta ao Item (TRI)}

A TRI engloba um conjunto de técnicas de modelagem que, por meio da análise de itens específicos, permitem a mensuração de determinadas características dos indivíduos avaliados (Edelen \& Reeve, 2007). Essas técnicas, conforme Andrade, Tavares e Valle (2000), permitem representar a relação entre $\mathrm{o}(\mathrm{s})$ traço(s) latente(s) pertencente(s) a um indivíduo e a probabilidade de este acertar determinado item. Entende-se por traço latente as características de um indivíduo que não podem ser observadas diretamente, como a proficiência em inglês ou o grau de satisfação de um consumidor. Um item pode ser representado por uma questão de prova, ou até mesmo, por uma pergunta relacionada ao grau de satisfação do indivíduo a um determinado produto ou serviço. No caso estudado neste artigo, o traço latente refere-se ao desempenho (proficiência) que expressa o conhecimento em contabilidade, mensurado por meio do conjunto de itens (questões) que compõem a prova do Enade/2012.

Nas últimas décadas, observou-se um crescimento na aplicação das técnicas derivadas da TRI, principalmente na área de avaliação educacional (Andrade et al., 2000). Os primeiros trabalhos relacionados a essa teoria surgiram na década de 50, com Lord (1952). Na sequência, vieram os trabalhos de Rasch (1960), Birnbaum (1968), Wright (1968) e Samejima (1969), este último com a proposta de um modelo de resposta gradual, já que os modelos anteriores eram aplicados apenas a respostas dicotômicas. Atualmente, existe uma vasta aplicação dos modelos da TRI pelo mundo, e mais informações sobre a origem dessa teoria podem ser consultadas nos trabalhos de Andrade et al. (2000), Bock (1997), Boomsma, Van Duijn e Snijders (2000), Van Der Linden e Hambleton (1997) e Moreira (2010).

Os modelos decorrentes da TRI são capazes de suprir algumas limitações da Teoria Clássica do Teste (TCT) ou Teoria Clássica da Medida (TCM), que é comumente utilizada na avaliação e seleção dos indivíduos. Na TCT, a avaliação é realizada por meio de escores brutos e padronizados. O escore de um indivíduo depende basicamente do número de acertos alcançados, sem considerar se esses acertos são oriundos de questões fáceis ou difíceis (Andrade et al., 2000).

Uma das diferenças que podem ser apontadas entre a TCT e a TRI está na forma como os modelos oriundos da TRI tratam o teste. Tomando como exemplo a área de avaliação educacional, na TRI, a avaliação dos itens que compõem o teste, isto é, uma prova, é considerada de forma conjunta, enquanto na TCT os itens são considerados individualmente, de forma que a pontuação alcançada em um item independe da pontuação alcançada em outros itens. Os benefícios apresentados pela TRI, neste caso, é que ela consegue capturar os indivíduos que respondem às questões de forma mais coerente, ou seja, acertando questões mais fáceis do que difíceis, de modo que valorize suas notas. Por outro lado, penaliza a nota de indivíduos que acertam mais questões difíceis que fáceis, uma vez que a lógica é que aqueles que acertam as questões mais difíceis deveriam também dominar as questões mais fáceis, o que pode estar relacionado com o acerto casual (ou 'chute', como é popularmente denominado) (Moreira, 2010).

Andrade et al. (2000) destacam que os maiores avanços da TRI estão relacionados com a criação de escalas interpretáveis; com a possibilidade de comparação entre indivíduos que fizeram testes diferentes, mas com itens pertencentes a uma mesma escala; e com a comparação entre indivíduos de populações diferentes, que realizaram testes com alguns itens em comum.

No Brasil, além da vasta aplicação dos modelos da TRI na área de avaliação educacional, tem-se observado o uso em outras diversas áreas, como grau de satisfação do consumidor, avaliação de intangíveis de empresas, gestão organizacional, avaliação de qualidade de vida, avaliações psicológicas, entre outras, que podem ser consultadas no trabalho de Moreira (2010). Conforme o autor, os estudos têm utilizado os mais variados modelos unidimensionais da TRI, com destaque para o modelo logístico de três parâmetros (ML3P). Neste estudo é utilizado o ML3P. Esse modelo contempla parâmetros de discriminação do item, dificuldade do item e probabilidade de acerto casual, diferentemente do modelo de Rasch, que somente leva em consideração a dificuldade. No próximo tópico, são apresentados alguns exemplos de estudos que empregaram a TRI para análise da prova do Enade, e pesquisas na área de Ciências Contábeis relacionadas ao Enade. 


\subsection{Trabalhos empíricos}

Internacionalmente, Bartlett, Peel e Pendlebury (1993) descobriram que o desempenho dos estudantes no terceiro ano do curso de Ciências Contábeis da University of Wales College of Cardiffestava mais relacionado ao próprio desempenho no primeiro ano do que a outras características, como demográficas, financeiras ou de investimentos. Byrne e Flood (2008) observaram acréscimo de desempenho geral, em Contabilidade Financeira e Contabilidade Gerencial, entre estudantes da Dublin City University que possuíam conhecimentos prévios em Contabilidade. Ambos os estudos utilizaram a teoria Clássica para mensuração do desempenho, com base na média alcançada pelos estudantes nas disciplinas Contabilidade Financeira e Gerencial.

Davidson (2003), ao analisar estudantes canadenses, observou que um desempenho superior em Ciências Contábeis em exames que incluem questões complexas, está relacionado a uma abordagem de estudo mais aprofundada e não apenas a técnicas superficiais de memorização. Fatores como o desempenho acadêmico anterior, motivação para realizar o curso e intenção de trabalhar na área contábil também contribuem para explicar o desempenho nos exames de avaliação. Diferentemente do presente estudo, o desempenho dos estudantes foi mensurado a partir de uma aplicação de teoria Clássica (análise clássica), ponderada pelo nível relativo de dificuldade envolvida em cada questão. Embora essa seja uma forma de buscar minimizar as distorções resultantes do uso da teoria Clássica básica, em que todas as questões têm o mesmo peso na avaliação, esse nível de dificuldade não se ajusta às características específicas do grupo de estudantes que realizou a prova.

Clinton e Kohlmeyer (2005) avaliaram estudantes norte-americanos e constataram que apesar de não haver diferenças significativas entre o desempenho de indivíduos submetidos a um processo educacional baseado em quizzes e a processos baseados em metodologias convencionais, havia uma diferença significativa na percepção de aprendizagem e motivação para estudar no grupo de estudantes submetidos ao método baseado em quizzes. Assim como Davidson (2003) e diferentemente do presente estudo, utilizaram a teoria Clássica para mensuração do desempenho dos estudantes. Uma ressalva acerca da abordagem de Clinton e Kohlmeyer (2005) é que a falta de significância na diferença entre as abordagens de ensino pode ser proveniente de distorções pelo uso da teoria Clássica. Uma possibilidade de reavaliação da efetividade do estudo baseado em quizzes é a mensuração da variável dependente (desempenho do estudante) com base na proficiência estimada pela TRI.

No Brasil, alguns estudos utilizaram como base a prova Enade para mensurar o desempenho de estudantes de Ciências Contábeis. Souza (2008) analisou os determinantes do desempenho dos alunos na prova Enade/2006. Ele identificou que variáveis, como o nível de conhecimento do aluno anterior ao seu ingresso no curso, a escolaridade do pai, o esforço pessoal e a renda familiar, influenciam no desempenho dos alunos avaliados. Santos (2012) ampliou o estudo de Souza (2008), analisando o efeito das variáveis individuais e institucionais no desempenho dos estudantes e os dados do Exame Nacional de cursos de 2002 e 2003 e o Enade/2006, apontando que variáveis, como gênero, horas dedicadas aos estudos, renda familiar e cursar o ensino médio em escola pública, interferem positivamente no desempenho dos alunos. Adicionalmente, instituições com o corpo docente formado por professores com mestrado e doutorado e com dedicação exclusiva também contribuem para um maior desempenho dos alunos.

Miranda (2011) investigou a relação entre o desempenho dos discentes e a qualificação dos docentes dos cursos de Ciências Contábeis. O autor utilizou como base para mensurar o desempenho dos estudantes os resultados do Enade/2009. Os resultados apontam que a qualificação acadêmica dos docentes das Instituições de Ensino Superior (IES) investigadas pode influenciar o desempenho dos alunos na prova do Enade. De forma similar, Santos, Cunha e Cornachione Junior (2009) observaram que o conceito dos cursos de Ciências Contábeis reflete em parte a titulação dos professores. Os autores utilizaram uma variável nominal de cinco categorias para avaliar o desempenho dos cursos. Cabe salientar que, antes da conversão para nominal, a forma de mensuração utilizada advém da teoria clássica. Cruz, Nossa, Balassiano e Teixeira (2013) não encontraram relação que confirme que a estrutura didático-pedagógica dos conteúdos curriculares influencie o desempenho dos estudantes que realizaram o Enade/2009. Somente houve confirmação de que o desempenho seja influenciado pela região geográfica do curso. 
Apesar de existirem estudos relacionados à prova do ENADE, na literatura nacional relacionada à área contábil, não foram identificados pesquisas que investigassem as relações entre os itens abordados na prova e a proficiência (desempenho) dos alunos com base na TRI. Dos estudos revisados, somente foram encontradas mensurações de desempenho dos estudantes com base na teoria Clássica, que, como pontuado na seção anterior, apresenta uma série de desvantagens em relação à TRI.

Alguns estudos de outras áreas de conhecimento analisaram a prova do Enade com a aplicação da teoria da Resposta ao Item (TRI). Exemplos incluem as áreas de Administração (Scher, Moreira, Correa, Schuch, Andrade \& Bortolotti, 2014), Estatística (Coelho, Ribeiro Junior \& Bonat, 2014), Psicologia (Primi et al., 2011) e Pedagogia (Lopes \& Vendramini, 2015).

Scher et al. (2014) analisaram a prova Enade/2009, realizada por alunos de Administração, utilizando o ML3P. Os resultados apontaram a viabilidade da utilização da TRI nos itens avaliados na prova do Enade e observaram também o ganho em relação à proficiência entre os ingressantes e concluintes. Coelho et al. (2014) aplicaram a TRI aos alunos que realizaram a prova Enade/2009 na área de Estatística; e observaram que poucos alunos apresentaram alta proficiência na prova, concentrando-se a maioria dos respondentes em uma proficiência média. Primi et al. (2011) analisaram a prova do Enade/2006, realizada pelos alunos ingressantes e concluintes de Psicologia; empregaram análise fatorial e o modelo de Rasch; apresentaram a construção de quatro faixas de desempenho, descrevendo, com base nos itens que compõem a prova, quais os conhecimentos, habilidades e competências eram necessários para o aluno demonstrar proficiência em cada faixa; e observaram uma concentração de alunos concluintes em faixas de proficiência mais elevadas e que em cursos com notas mais elevadas no Enade a diferença entre o desempenho entre ingressantes e concluintes é menor. Lopes e Vendramini (2015) analisaram a prova Enade/2005, realizada pelos alunos de Pedagogia. Semelhantemente ao estudo de Primi et al. (2011), também empregaram o modelo de Rasch e constatam que a prova engloba questões de dificuldade mediana similar à proficiência média dos alunos, portanto, adequada.

Observa-se, entre as pesquisas de outras áreas que empregaram a TRI, que a avaliação efetuada apresenta formas mais detalhadas de aferição da proficiência dos estudantes, nas quais, tanto os itens que compõem as provas quanto os respondentes são colocados em uma mesma escala de mensuração, possibilitando indicar quais são os conhecimentos especificamente dominados pelos estudantes. Entende-se que a aplicação da TRI na prova Enade realizada pelos alunos da área de Ciências Contábeis, pode também contribuir para o entendimento dos conhecimentos e habilidades dominados pelos alunos investigados, de acordo com seu nível de proficiência.

\section{Procedimentos Metodológicos}

Para mensuração do desempenho (proficiência) dos estudantes de Ciências Contábeis no Enade/2012, foi utilizado o ML3P da TRI. As análises foram realizadas com base na estimação realizada por meio do software BILOG-MG e nos gráficos gerados no software R (R Development Core Team, 2012). 


\subsection{População e amostra}

A população do estudo é constituída pelos alunos concluintes dos cursos de Ciências Contábeis do Brasil. Foram inscritos para a prova do Enade/2012 um total de 57.248 estudantes (Inep, 2014). Inicialmente, do total de alunos, foram identificados 47.124 alunos com dados válidos, regularmente matriculados em cursos de Ciências Contábeis do Brasil, convocados pelo Ministério da Educação (MEC) e que compareceram para a realização do exame; selecionaram-se os alunos que realizaram todas as provas objetivas, tanto de Conhecimentos Gerais como de Conhecimentos Específicos; e observou-se a existência de 26 alunos que, apesar de terem comparecido, entregaram a prova sem resolução, ou seja, não responderam às questões. Assim, a amostra final é composta por 47.098 alunos que realizaram a prova do Enade/2012. Os dados foram extraídos do site do Instituto Nacional de Estudos e Pesquisas Educacionais Anísio Teixeira (Inep) em 26 de outubro de 2015.

A idade dos alunos variou entre 19 e 79 anos, cuja média foi de 29 anos. A maior parcela de alunos possuía idade entre 21 e 25 anos (19.756 pessoas - 42\%); 12.556 (27\%) dos alunos situavam-se entre 26 e 30 anos; 7.135 (15\%) encontravam-se entre 31 e 35 anos; e 7.534 (16\%) acima de 35 anos. Somente 177 estudantes tinham idade até 20 anos. A maior parte dos alunos (94\%) realizou o curso no período noturno. Observou-se predominância de estudantes do sexo feminino (59\%) e provenientes das regiões Sudeste (39\%) e Sul (24\%). A região Norte concentrou o menor número de estudantes (6\%), seguida pelas regiões Centro-Oeste (13\%) e Nordeste (18\%). Dos estudantes que compõem a amostra, $16 \%$ pertencem a Instituições de Ensino Superior (IES) públicas, e 84\% , a instituições privadas.

\subsection{Mensuração do desempenho dos alunos (proficiência)}

\subsubsection{Prova do Enade}

A prova do Enade/2012 é composta de questões discursivas e objetivas (tanto de conhecimentos gerais, como de conhecimentos específicos). Ao todo são 40 (quarenta) questões, divididas em 10 (dez) questões de formação geral (duas discursivas e oito de múltipla escolha) e 30 (trinta) de conhecimentos específicos (três discursivas e vinte e sete de múltipla escolha).

As questões de formação geral envolvem conhecimentos de arte e cultura, avanços tecnológicos, democracia, ética e cidadania, ecologia e biodiversidade, políticas públicas, relações de trabalho, responsabilidade social, entre outros. O intuito desse grupo de questões é avaliar características relacionadas a um profissional ético, competente e comprometido com a sociedade em que vive (Inep, 2014).

O componente de conhecimento específico envolve questões de Teoria da Contabilidade, Ética Profissional, Contabilidade Financeira, Contabilidade e Análise de Custos, Contabilidade Gerencial e Controladoria, entre outros conhecimentos. O objetivo dessas questões é avaliar as competências dos estudantes em utilizar terminologias e linguagem das Ciências Contábeis, apresentar visão sistêmica e interdisciplinar, domínio das etapas de identificação, reconhecimento, mensuração e evidenciação, capacidade crítico-analítica, gerar informações para tomada de decisões, interpretar e aplicar a normatização contábil, entre outras competências (Inep, 2014).

Para o estudo, foram consideradas, exclusivamente, as questões objetivas, ou seja, 35 (trinta e cinco) questões (oito de formação geral e vinte e sete de conhecimentos específicos), que foram tratadas como itens dicotomizados e avaliadas por meio do Modelo Logístico Unidimensional de Três Parâmetros da TRI (ML3P), apresentado com maiores detalhes na seção 3.2.2. 


\subsubsection{Modelo de Mensuração da TRI}

A mensuração do desempenho foi desenvolvida por meio da TRI em que foi construída uma escala para avaliação dos níveis de proficiência dos alunos no Enade/2012. Nessa forma de mensuração, todos os itens que compõem o instrumento de avaliação (prova) são colocados em uma mesma escala de medida da proficiência. Por meio dessa escala, foi possível posicionar todos os itens que compuseram a prova em níveis "âncora" para a realização de interpretações acerca do desempenho requerido no exame.

Os modelos propostos na literatura, originados da TRI, se fundamentam, de acordo com Andrade et al. (2000), em três fatores, a saber: (i) natureza do item, que pode ser dicotômico ou não dicotômico; (ii) número de populações envolvidas, representado por uma ou mais de uma; e (iii) quantidade de traços latentes mensurados, que pode ser um ou mais de um (unidimensional ou multidimensional).

Neste estudo, é utilizado um modelo unidimensional, representado pelo traço latente "conhecimento em Contabilidade", considera-se uma única população, isto é, os alunos de Ciências Contábeis que realizaram a prova Enade/2012; e utilizam-se itens dicotomizados.

O ML3P é aplicável quando os itens são dicotômicos ou politômicos (itens com duas ou mais categorias) com uma única opção de resposta correta. Neste último caso, os itens politômicos devem ser ajustados (dicotomizados) em duas categorias, isto é, certo e errado. Esse modelo é aplicável em casos que se deseja avaliar a dificuldade do item, a discriminação e a probabilidade de resposta correta dada por indivíduos de baixa habilidade (Andrade et al., 2000).

O ML3P é representado na Figura 1:

$P\left(U_{i j}=1 \mid \theta_{j}\right)=c_{i}+\left(1-c_{i}\right) \frac{1}{1+e^{-a_{i}\left(\theta_{j}-b_{i}\right)}}$
$\operatorname{com} i=1,2,3, \ldots, I, \mathrm{e} j=1,2,3, \ldots, n$,
Em que:
$U_{i j}:$ variável dicotômica que assume os valores 1 (um), quando o individuo $j$ responde corretamente o item $i$,
ou 0 (zero), caso contrário;
$\theta_{j}:$ Representa a habilidade (traço latente) do $j$-ésimo indivíduo pesquisado;
$P\left(U_{i j}=1 \mid \theta_{j}\right)$ : É a probabilidade de um individuo $j$ com habilidade $\theta_{j}$ responder corretamente o item $i$ e é
denominado de Função de Resposta do Item - (FRI);
$a_{i}:$ Representa o parâmetro de discriminação do item $i$, cujo valor do parâmetro é proporcional à inclinação da
Curva Característica do Item $-\left(\right.$ CCI) no ponto $b_{i}$.
$b_{i}:$ representa o parâmetro de dificuldade do item $i$, medido na mesma escala de habilidade;
$c_{i}:$ é o parâmetro do item que representa a probabilidade de indivíduos com baixa habilidade responderem
corretamente o item $i$, isto é, representa a probabilidade de acerto casual.

Fonte: adaptado de Andrade et al. (2000, pp. 9-10).

Figura 1. Modelo Logístico Unidimensional de Três Parâmetros (ML3P)

A estimação dos parâmetros dos modelos baseados na TRI geralmente é realizada pelo Método da Máxima Verossimilhança Marginal, com a aplicação conjunta de um processo iterativo, como o algoritmo Newton-Raphson ou Scoring de Fisher, ou procedimentos bayesianos, conforme aponta Andrade et al. (2000). 
Na Figura 2, é possível visualizar a Curva Característica do Item (CCI).

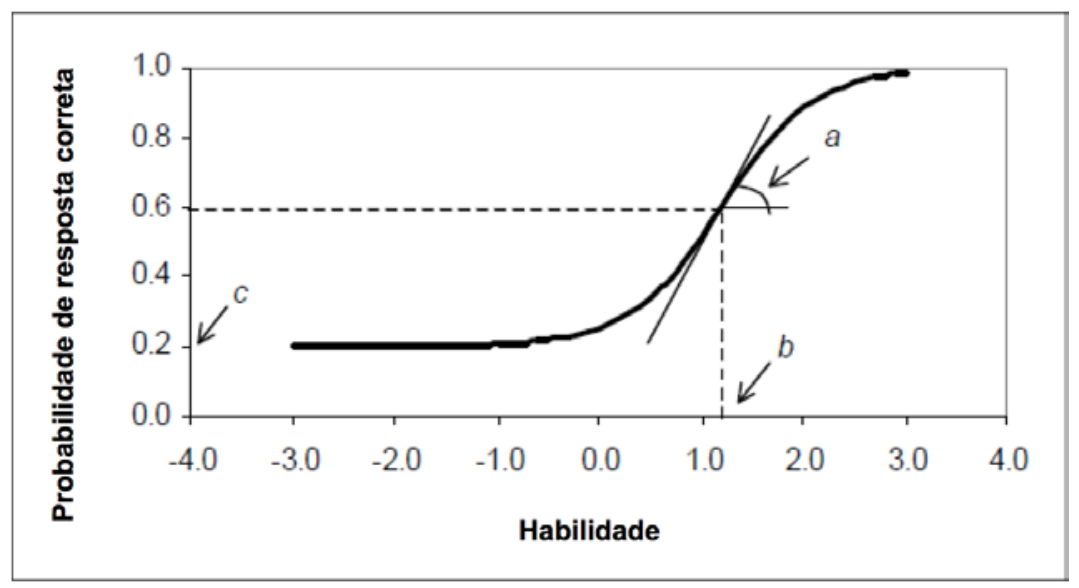

Fonte: Andrade et al. (2000, p. 11).

Figura 2. Curva Característica do Item (CCl)

A CCI representa a relação existente entre a probabilidade de um indivíduo responder corretamente a um determinado item $\left(P\left(U_{i j}=1 \mid \theta_{j}\right)\right)$, dada sua habilidade, e os parâmetros do ML3P $a_{i}, b_{i}$ e $c_{i}$, que representam, respectivamente, a inclinação da curva (discriminação), a posição do item na escala (dificuldade); e a probabilidade de acerto casual de indivíduos com baixa habilidade. O eixo Y representa a probabilidade de resposta correta de um indivíduo, enquanto o eixo $\mathrm{X}$ demonstra a habilidade referente ao traço latente avaliado.

Na TRI, de acordo com Andrade et al. (2000), a proficiência (habilidade) mensurada de um indivíduo pode assumir um valor real entre $-\infty \mathrm{e}+\infty$. Nesse caso, é necessário estabelecer uma origem e uma unidade de medida para a escala que será construída para o traço latente que é avaliado. A escala padrão geralmente utilizada nos softwares que estimam os modelos da TRI é representada pela média 0 e desvio-padrão 1, isto é, escala $(0,1)$. É possível modificar essa escala, desde que sejam mantidas as relações de ordem existentes entre os parâmetros do modelo. Informações sobre a transformação de escalas podem ser consultadas em Andrade et al. (2000). Neste estudo adotou-se a escala $(0,1)$ para análise do desempenho dos estudantes de Ciências Contábeis no Enade/2012.

No ML3P, o parâmetro $a_{i}$ representa a discriminação do item avaliado. Itens com valores excessivamente baixos nesse parâmetro indicam um baixo poder de discriminação, isto é, a probabilidade do indivíduo com baixa proficiência responder corretamente ao item é a mesma de um indivíduo com alta proficiência. Em geral, é esperado, conforme a escala utilizada $(0,1)$, que para um item possuir boa discriminação, ele apresente um parâmetro $a_{i}$ maior que 1 (Andrade et al., 2000), apesar de que itens com parâmetros acima de 0,7 também são aceitáveis (Scher et al., 2014). Isso porque o parâmetro $a_{i}$ é proporcional à derivada da tangente da curva da função logística no ponto de inflexão. Assim, curvas mais íngremes (com altos valores para este parâmetro) distinguem os indivíduos em basicamente dois grupos: os que dominam o conhecimento do item e aqueles que não o dominam. Por outro lado, valores baixos para esse parâmetro indicam que o item possui baixo poder de discriminação, em que estudantes com habilidades diferentes têm praticamente a mesma probabilidade de acertar o item (Andrade et al., 2000).

$\mathrm{O} b_{i}$ é o parâmetro de dificuldade do item - quanto maior, mais difícil é o item, e vice-versa ou seja, assim, apenas aqueles indivíduos com proficiência mais alta é que terão maior probabilidade de acertá-lo - e é conhecido também como parâmetro de localização, uma vez que é o parâmetro que auxilia a verificação da posição do item na escala de proficiência (Scher et al., 2014). Para a escala $(0,1)$ que considera uma média igual a zero e desvio-padrão igual a um, espera-se que os valores apresentados pelos itens para o parâmetro $b_{i}$ estejam entre $-2 \mathrm{e}+2$ (Andrade et al., 2000). 
O parâmetro $c_{i}$ representa a probabilidade de um individuo com baixa proficiência responder corretamente a um determinado item. O seu valor representa a quantidade de alternativas que compõem o item. Assim, para um item composto por cinco alternativas, em que a probabilidade teórica de acerto de um indivíduo assinalar qualquer uma das alternativas é 0,2 , pode-se estabelecer uma margem de tolerância (acima e abaixo de 0,2), em que a resposta fornecida pelo estudante poderia ser considerada como apenas um acerto casual e, não, o domínio do conhecimento do item. Desse modo, espera-se que o parâmetro $c_{i}$ assuma um valor entre 0,1 e 0,3 (Scher et al., 2014).

Realizadas a mensuração da proficiência dos alunos e a análise dos parâmetros apresentados pelo modelo estimado, a próxima etapa foi analisar o desempenho dos alunos da população investigada. Para isso, no próximo tópico, é discutido como foi realizada a interpretação da escala.

\subsection{Análise do desempenho dos alunos (proficiência)}

A partir da mensuração da proficiência dos alunos, todas as questões foram posicionadas em uma mesma escala, ordenadas de acordo com o parâmetro de dificuldade dos itens $\left(b_{i}\right)$. Foram considerados como itens "âncora" aqueles que atenderam simultaneamente aos critérios apresentados na Figura 3.

$$
\begin{aligned}
& \text { 1. } P(U=1 \mid \theta=Z)>0,65 \\
& \text { 2. } P(U=1 \mid \theta=Y)<0,50 ; e \\
& \text { 3. } P(U=1 \mid \theta=Z)-P(U=1 \mid \theta=Y)>0,30 .
\end{aligned}
$$

Fonte: Andrade et al. (2000, p. 110)

Figura 3. Critérios para definição de níveis "âncora"

Dessa forma, para que um item seja considerado "âncora", ele necessita ser respondido corretamente pela maior parte dos indivíduos (65\%) com a proficiência indicada no nível da escala e por uma proporção menor de indivíduos, isto é, no máximo, $50 \%$ daqueles que possuem um nível de proficiência inferior. Adicionalmente, é necessário que exista uma diferença de 30\% entre indivíduos com diferentes níveis de habilidade que acertaram o item (Andrade et al., 2000). No entanto, devido à dificuldade de atendimento simultâneo dos três critérios, foram também considerados como itens "quase âncora" aqueles que atendessem a pelo menos dois dos critérios mencionados.

Os itens identificados como itens "âncora" ou "quase âncoras", já definidos conforme a Figura 3, foram posteriormente analisados e relacionados aos objetivos da questão, às competências exigidas e aos objetos de conhecimento envolvidos, estabelecidos pelo Inep na Matriz de Avaliação da Prova Enade/2012 de Ciências Contábeis, demonstrado na Tabela 1. Essa análise foi assim realizada porque, estatisticamente, a TRI é capaz de separar as faixas de proficiência e, pedagogicamente, é possível apontar os conhecimentos e competências exigidos pela prova em cada faixa de proficiência. 
Tabela 1

Matriz de avaliação da Prova Enade/2012 de Ciências Contábeis

\begin{tabular}{|c|c|c|}
\hline Classificação & Componente de Formação Geral & Componente Específico \\
\hline Objetivos & $\begin{array}{l}\text { Investigar a formação de um profissional ético, } \\
\text { competente e comprometido com a sociedade } \\
\text { em que vive. }\end{array}$ & $\begin{array}{l}\text { I - avaliar o nível de compreensão das questões } \\
\text { científicas, técnicas, sociais, econômicas e } \\
\text { financeiras; } \\
\text { II - aferir o grau de domínio do raciocínio lógico na } \\
\text { solução de questões em diferentes cenários; } \\
\text { III - verificar a capacidade de análise crítico- } \\
\text { analítica; } \\
\text { IV - avaliar o nível do raciocínio quantitativo; } \\
\text { V - verificar a capacidade de visão sistêmica e } \\
\text { holística; } \\
\text { VI - analisar a capacidade de comunicação e } \\
\text { interação; } \\
\text { VII - verificar a compreensão das inovações } \\
\text { tecnológicas aplicadas; } \\
\text { VIII - avaliar a percepção sobre a conduta ética. }\end{array}$ \\
\hline
\end{tabular}

I - utilizar terminologias e linguagem das Ciências

Contábeis;

II - exercer atividades contábeis com visão

Capacidades: ler e interpretar textos; analisar sistêmica e interdisciplinar;

e criticar informações; extrair conclusões por indução e/ou dedução; estabelecer relações, comparações e contrastes em diferentes situações; detectar contradições; fazer
Competências e Habilidades Avaliadas escolhas valorativas avaliando consequências; questionar a realidade; e argumentar coerentemente.

Competências: projetar ações de intervenção; propor soluções para situações-problema; construir perspectivas integradoras; elaborar sínteses; administrar conflitos; e atuar segundo princípios éticos.
III - ter domínio do processo de identificação, reconhecimento, mensuração e evidenciação; IV - demonstrar capacidade crítico-analítica, envolvendo atividades de apurações, auditorias, perícias, arbitragens e quantificações de informações financeiras, patrimoniais e governamentais;

V - demonstrar capacidade de identificar e gerar informações para o processo decisório; VI - interpretar e aplicar a normatização inerente à contabilidade;

VII - ter capacidade de identificar a necessidade de informações dos usuários para subsidiar o desenvolvimento de sistemas de informação; VIII - compreender a conduta ética no exercício das atividades da área contábil.

Arte e cultura; avanços tecnológicos; ciência, tecnologia e inovação; democracia, ética e cidadania; ecologia e biodiversidade; globalização e geopolítica; políticas públicas: educação, habitação, saneamento,

Objeto de saúde, transporte, segurança, defesa,

Conhecimento desenvolvimento sustentável; relações de trabalho; responsabilidade social: setor público, privado, terceiro setor; sociodiversidade: multiculturalismo, tolerância, inclusão/exclusão, relações de gênero; tecnologias de informação e comunicação; vida urbana e rural; e violência.
I - Teoria da Contabilidade;

II - Ética Profissional;

III - Contabilidade Financeira;

IV - Análise de Demonstrações Contábeis;

V- Contabilidade e Análise de Custos;

VI - Contabilidade Gerencial e Controladoria;

VII - Administração Financeira;

IX - Auditoria e Perícia;

X - Legislação societária, empresarial, trabalhista e tributária;

XI - Métodos quantitativos aplicados à

Contabilidade;

XII - Sistemas e tecnologias de informações.
VIII - Contabilidade Aplicada ao Setor Público;

Fonte: elaborado pelos autores com base em Inep (2014). 
Buscou-se, nesta etapa, a identificação dos motivos para o posicionamento apresentado pelos itens em cada ponto da escala construída, em função do nível de dificuldade apresentado pelas questões. Nesta análise, foi levada em consideração a complexidade relativa aos objetivos, às competências e aos objetos de conhecimento, inclusive as questões de interdisciplinaridade envolvidas no conteúdo da questão. Esta análise, juntamente com a criação da escala de medida e identificação dos níveis "âncora" é apresentada no próximo tópico.

\section{Análise dos Resultados}

Na sequência são apresentados os resultados da aplicação da TRI para mensuração da proficiência (desempenho) dos estudantes de Ciências Contábeis na prova Enade/2012. Cabe salientar que, das 35 questões analisadas, oito foram excluídas, uma vez que apresentaram coeficientes de correlação bisserial muito baixos, inadequados para a estimação do modelo, podendo causar distorções nas estimações realizadas. As questões excluídas foram: 05 e 08, pertencentes ao grupo de conhecimento geral; e 10, 19, 21, 28, 29 e 32, pertencentes ao grupo de conhecimentos específicos. Essa exclusão se deve ao fato de os problemas identificados nos itens apontados não possibilitarem a convergência na estimação do modelo pelo método de máxima verossimilhança marginal. Em outras palavras, os problemas apresentados pelos itens são de tamanha magnitude que impossibilitam a realização da calibração de parâmetros da TRI. Por se tratarem de itens com baixos coeficientes de correlação bisserial, são questões ineficientes para explicação do desempenho dos estudantes, uma vez que indivíduos com alta ou baixa proficiência possuem probabilidades próximas de acertar o item e, portanto, não auxiliam na estimação e diferenciação do desempenho dos estudantes.

\subsection{Estimação dos Parâmetros}

A Tabela 2 apresenta os parâmetros de discriminação $\left(a_{i}\right)$, dificuldade $\left(b_{i}\right)$ e acerto casual $\left(c_{i}\right)$ dos itens avaliados, com seus respectivos erro-padrão (EP). Tais parâmetros foram estimados no software BILOG-MG ${ }^{\oplus}$ com escala 0,1 .

Como é possível visualizar na Tabela 2, os parâmetros $a_{i}$ dos itens avaliados, em geral, apresentam-se acima de 0,7 . O parâmetro $a_{i}$ indica a discriminação de cada item - quanto maior o valor deste parâmetro, maior é o seu poder de discriminação. Em outras palavras, indica o quanto cada item consegue diferenciar aqueles indivíduos que possuem o conhecimento avaliado daqueles que não o possuem. Os itens com maior poder de discriminação foram os itens 34, 14 e 11. É possível visualizar, na Figura 4, que são os itens que possuem as curvas características dos itens mais inclinadas. 
Tabela 2

\section{Estimativas dos Parâmetros dos Itens do ML3P}

\begin{tabular}{|c|c|c|c|c|c|c|}
\hline Itens & $a$ & E.P. & $\boldsymbol{b}$ & E.P. & c & E.P. \\
\hline 1 & 0,8271 & 0,0602 & 0,4967 & 0,1252 & 0,2787 & 0,0322 \\
\hline 2 & 0,5854 & 0,0314 & 0,8857 & 0,1042 & 0,0929 & 0,0257 \\
\hline 3 & 0,4705 & 0,0517 & 2,0241 & 0,1600 & 0,1592 & 0,0363 \\
\hline 4 & 0,4435 & 0,0217 & 0,5318 & 0,1430 & 0,0893 & 0,0271 \\
\hline 6 & 0,4496 & 0,0397 & 0,9140 & 0,2540 & 0,1740 & 0,0456 \\
\hline 7 & 0,9238 & 0,0527 & 0,6838 & 0,0732 & 0,1814 & 0,0232 \\
\hline 11 & 2,0006 & 0,0998 & 1,4364 & 0,0196 & 0,2222 & 0,0051 \\
\hline 12 & 1,6104 & 0,0707 & 0,7517 & 0,0265 & 0,2123 & 0,0105 \\
\hline 13 & 1,3361 & 0,0963 & 2,3545 & 0,0571 & 0,1704 & 0,0054 \\
\hline 14 & 2,0909 & 0,2160 & 2,7792 & 0,0841 & 0,1400 & 0,0025 \\
\hline 15 & 0,9278 & 0,0791 & 1,9782 & 0,0507 & 0,2586 & 0,0131 \\
\hline 16 & 0,8736 & 0,0190 & 0,3576 & 0,0241 & 0,0238 & 0,0074 \\
\hline 17 & 1,3547 & 0,1602 & 3,1178 & 0,1465 & 0,1816 & 0,0043 \\
\hline 18 & 1,4574 & 0,1153 & 2,5441 & 0,0692 & 0,1679 & 0,0044 \\
\hline 20 & 0,4851 & 0,0478 & 2,2916 & 0,1151 & 0,1195 & 0,0290 \\
\hline 22 & 0,4242 & 0,0791 & 4,3488 & 0,2956 & 0,1510 & 0,0275 \\
\hline 23 & 1,3846 & 0,0663 & 0,6966 & 0,0373 & 0,2553 & 0,0133 \\
\hline 24 & 0,8050 & 0,0372 & 1,3116 & 0,0429 & 0,0596 & 0,0144 \\
\hline 25 & 0,9345 & 0,0366 & $-0,2786$ & 0,0876 & 0,1214 & 0,0306 \\
\hline 26 & 0,6932 & 0,0192 & 0,7049 & 0,0381 & 0,0330 & 0,0101 \\
\hline 27 & 1,2058 & 0,0566 & 1,2264 & 0,0274 & 0,1281 & 0,0106 \\
\hline 30 & 1,9193 & 0,1551 & 2,5244 & 0,0613 & 0,1313 & 0,0029 \\
\hline 31 & 0,8399 & 0,1058 & 3,3597 & 0,1826 & 0,1572 & 0,0094 \\
\hline 33 & 0,5174 & 0,0838 & 4,7095 & 0,3753 & 0,0834 & 0,0151 \\
\hline 34 & 2,1004 & 0,1432 & 1,9395 & 0,0321 & 0,2558 & 0,0039 \\
\hline 35 & 0,7550 & 0,0443 & 1,1123 & 0,0703 & 0,1110 & 0,0219 \\
\hline
\end{tabular}

Legenda: $a$ = parâmetro de discriminação da TRl; $b$ = parâmetro de dificuldade da TRI; c = probabilidade de acerto casual segundo a TRl; E.P = Erro-Padrão.

Nota: Os parâmetros a, b e c apresentados na tabela se referem aos parâmetros agrupados dos itens.

Fonte: elaborado pelos autores.

O parâmetro $b_{i}$ representa a dificuldade de cada item - quanto maior seu valor, maior a proficiência necessária dos estudantes para responder a questão. Conforme a Tabela 2 , os itens que possuem maior grau de dificuldade para os estudantes avaliados foram os 33, 22 e 31. Essas questões requerem conhecimento interdisciplinar dos alunos relacionados a Contabilidade Financeira, Teoria da Contabilidade, Auditoria, Sistemas de Informações e as Legislações Societária e Tributária. Ao analisar as questões, percebe-se que exigem do aluno domínio de terminologias contábeis, capacidade crítico-analítica, com visão sistêmica e holística para interpretar e aplicar a teoria e normatização inerente à Contabilidade. Por outro lado, os itens mais fáceis para os estudantes foram os 25,16 e 1, os quais requerem apenas conhecimentos básicos acerca da normatização contábil e de auditoria. $\mathrm{O}$ item 1 refere-se a uma questão de conhecimento geral e demanda capacidade de leitura e intepretação de textos. Em geral, as questões 25 e 16, de conhecimentos específicos, exigem apenas a compreensão do texto da norma profissional, não sendo exigida capacidade crítico-analítica do estudante. 
É necessário observar que, conforme menciona Andrade et al. (2000), por definição matemática inerente ao modelo utilizado, espera-se que os itens apresentem parâmetros $b_{i}$ entre $-2 \mathrm{e}+2$, quando se adota a escala 0,1. Contudo, observou-se que os itens avaliados na prova Enade/2012 apresentam um grau de dificuldade alto para os estudantes avaliados, isto é, as questões constantes na prova estão muito acima da proficiência do grupo analisado.

A Figura 4 apresenta os gráficos com as curvas características dos itens (CCI). O eixo X representa a proficiência do estudante e o eixo Y representa sua probabilidade de resposta correta do mesmo.

Item trace lines

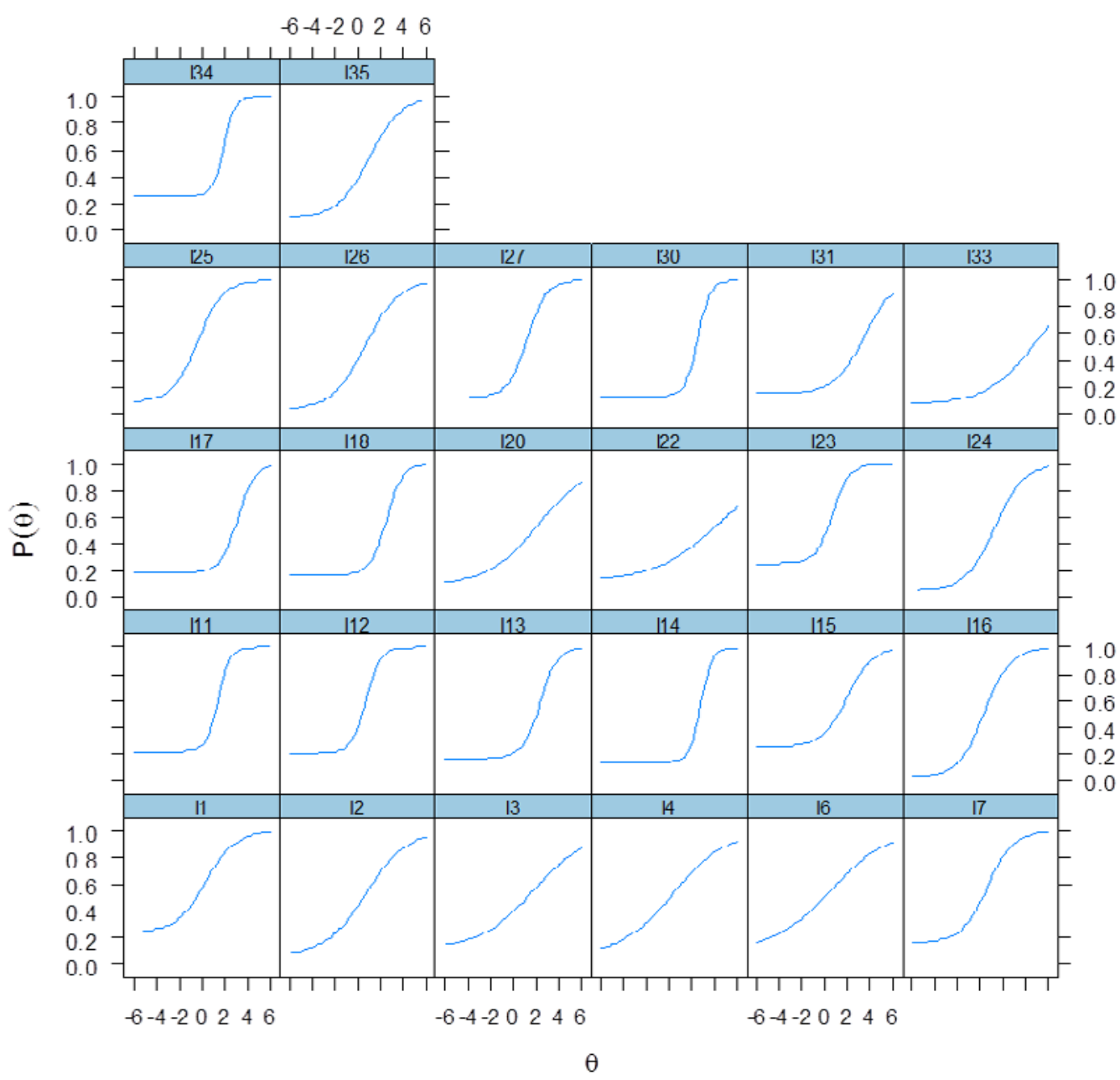

Fonte: elaborado pelos autores.

Figura 4. Curva Característica dos Itens (CCl)

Na Figura 4 é possível visualizar a variação na inclinação das curvas dos itens. Essa inclinação está relacionada ao parâmetro $a_{i}$, isto é, a discriminação dos itens avaliados. Conforme explicado na seção 3.2.2, essas curvas expressam a capacidade de discriminação dos itens entre indivíduos que dominam o conhecimento e aqueles que não o dominam. Por representar a derivada do ponto de inflexão da curva (CCI), a Figura 4 deve ser visualizada mais em função da característica apresentada pela curva do item do que em relação aos valores de $\theta$ e $\mathrm{P}(\theta)$. Em outras palavras, itens com curvas (CCI) menos íngremes ou mais próximos de retas possuem menor capacidade de discriminação. Complementarmente à Tabela 1 , itens que possuem parâmetros $a_{i}$ mais baixos apresentam uma CCI menos acentuada, como é o caso dos itens $22,4,6,3,20$ e 33. De forma inversa, itens com parâmetros $a_{i}$ mais altos, a exemplo dos itens 34,14 , $11,30,12$ e 18, apresentam uma CCI mais acentuada. 
A Figura 5 exibe a Função de Informação do Teste (FIT). Essa medida é formada pela soma das funções de informação de todos os itens.

\section{Test Information}

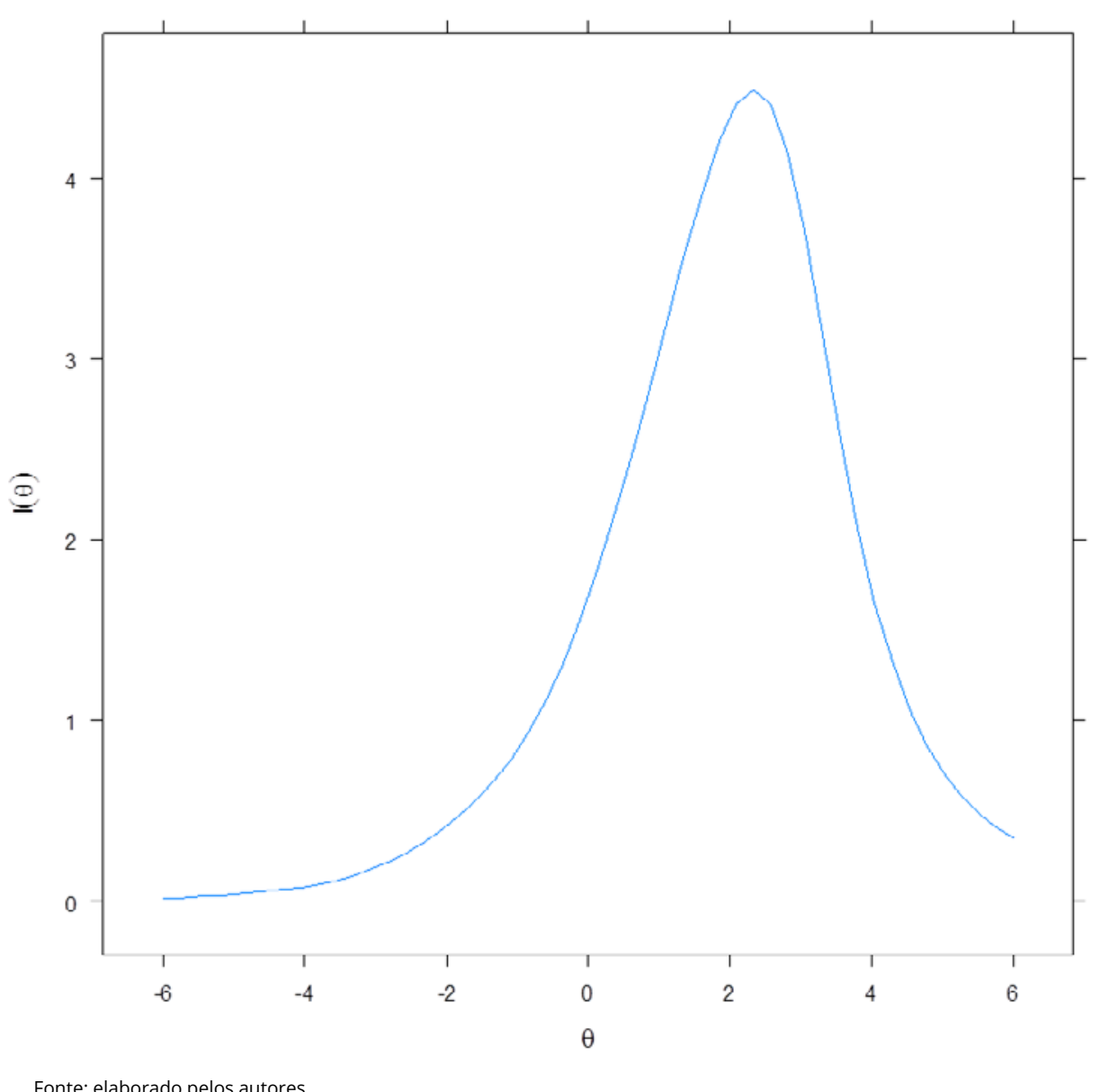

Figura 5. Função de Informação do Teste

Conforme apresenta a Figura 5, a FIT possui maior quantidade de informação no intervalo de 0 a 4 da escala. Isso representa que a prova Enade/2012, aplicada aos alunos de Ciências Contábeis, apresentou alta dificuldade para os estudantes investigados. Pode-se observar que apenas indivíduos com proficiência igual ou superior a 2 têm alta probabilidade de apresentar um bom desempenho. Assim, refere-se a um instrumento de avaliação mais adequado para mensurar o traço latente de estudantes com proficiência próxima a 2.

Na Figura 6, é possível visualizar a distribuição da proficiência dos estudantes dividida por regiões do País. A divisão por região foi adotada em função dos resultados apresentados por Cruz et al. (2013), que constataram diferenças significativas de desempenho entre estudantes de diferentes regiões para o Enade de 2009. 


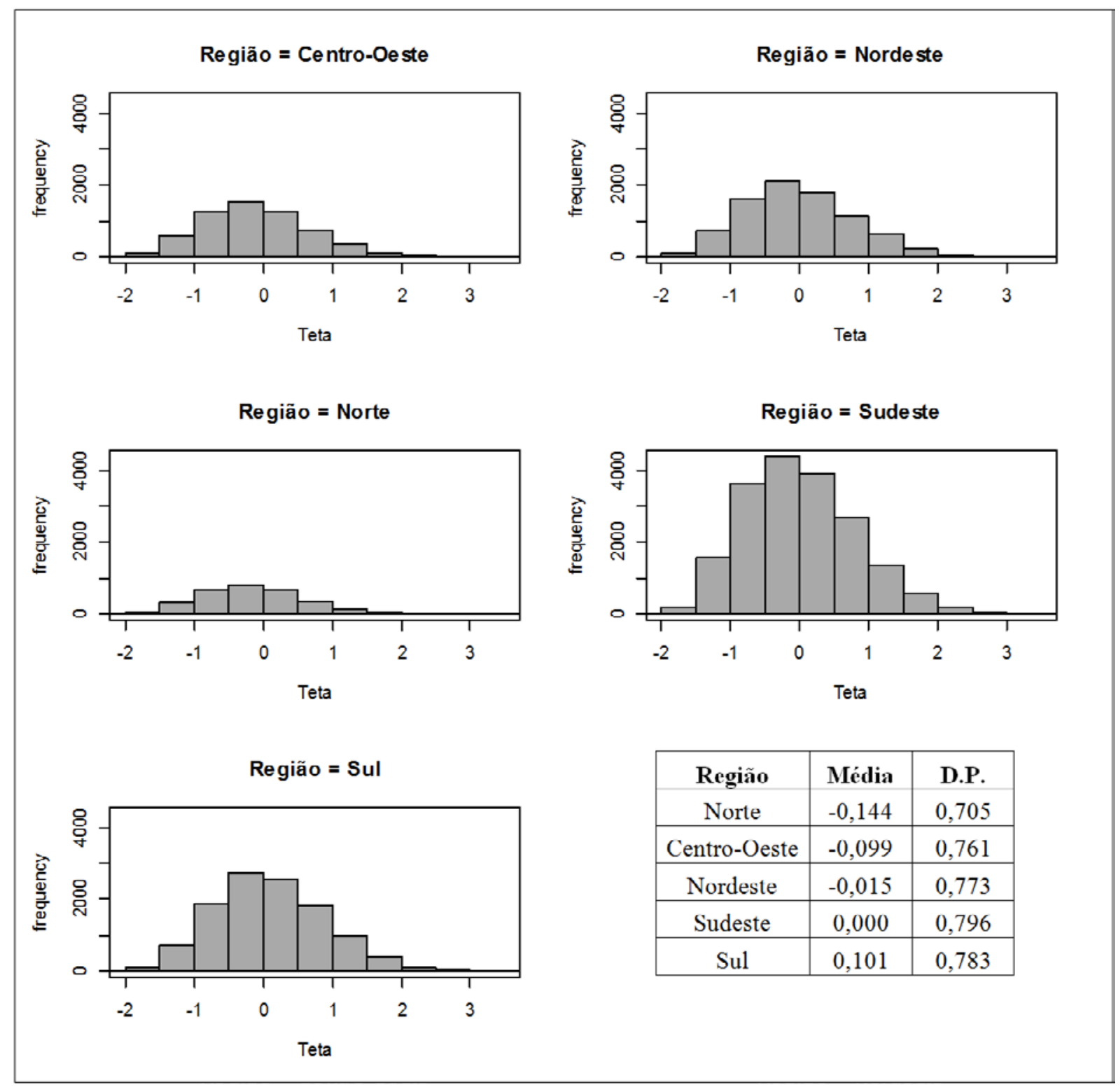

Fonte: elaborado pelos autores.

Figura 6. Distribuição da Proficiência (D.P.) por Região do País

É possível observar, na Figura 6, que, independente da região do Brasil a que o estudante pertença, sua proficiência tende a estar situada abaixo de 0 . Como observado anteriormente, a prova do Enade demonstrou um alto grau de dificuldade para o grupo que realizou a prova.

Em uma análise complementar da média de cada grupo de estudantes por região, observa-se que os alunos da região Sul possuem uma média de proficiência $(0,101)$ levemente superior às demais regiões. $\mathrm{O}$ contrário é observado para a região Norte, na qual os alunos possuem uma média de proficiência $(-0,144)$ um pouco mais baixa. Esses resultados corroboram os achados de Cruz et al. (2013), à medida em que os estudantes das regiões Nordeste, Norte e Centro-Oeste apresentam desempenhos mais baixos. Na Tabela 3, são apresentadas as médias das proficiências dos alunos estimadas por meio do ML3P da TRI, de acordo com algumas características. 
Tabela 3

Proficiência dos estudantes por características

\begin{tabular}{llccc}
\hline \multicolumn{2}{l}{ Característica } & $\mathbf{n}$ & Média & D.P. \\
\hline \multirow{2}{*}{ Ensino Médio } & Escola Pública & 13.371 & 0,042 & 0,824 \\
\cline { 2 - 5 } & Escola Privada & 33.727 & $-0,017$ & 0,764 \\
\hline \multirow{2}{*}{ Escolaridade da Mãe } & Ensino Superior & 6.474 & 0,054 & 0,855 \\
\cline { 2 - 5 } & Outra & 40.624 & $-0,009$ & 0,769 \\
\hline \multirow{2}{*}{ Escolaridade do Pai } & Ensino Superior & 5.666 & 0,092 & 0,866 \\
\cline { 2 - 5 } & Outra & 41.432 & $-0,013$ & 0,769 \\
\hline \multirow{2}{*}{ Horas Estudo Extraclasse } & Acima de 3h & 15.439 & 0,096 & 0,809 \\
\cline { 2 - 5 } & Menos de 3h & 31.659 & $-0,047$ & 0,764 \\
\hline Instituição de & Pública & 7.610 & 0,184 & 0,846 \\
\cline { 2 - 5 } Ensino Superior & Privada & 39.488 & 0,035 & 0,764 \\
\hline
\end{tabular}

Fonte: elaborado pelos autores.

Na Tabela 3, pode ser visualizado que alunos que cursaram o ensino médio em escola pública, que tanto o pai como a mãe possuem ensino superior, que dedicam mais horas de estudos extraclasse e que estudam em IES públicas, possuem médias de proficiência levemente superiores que aqueles sem essas características. Vale salientar que a maior diferença entre a média de proficiências ocorre entre estudantes provenientes de IES públicas e privadas. Estes resultados corroboram os achados de Souza (2008) e Santos (2012), realizados com base em provas anteriores do Enade.

No próximo tópico, é apresentada a escala de proficiência (desempenho) para a prova Enade/2012.

\subsection{Escala de Proficiência (Desempenho)}

A escala de Proficiência dos estudantes que realizaram a prova Enade/2012 é representada na Figura 7. Todos os itens estão representados na escala, porém apenas os itens destacados (em negrito) referem-se a itens "âncora" ou quase "âncora".

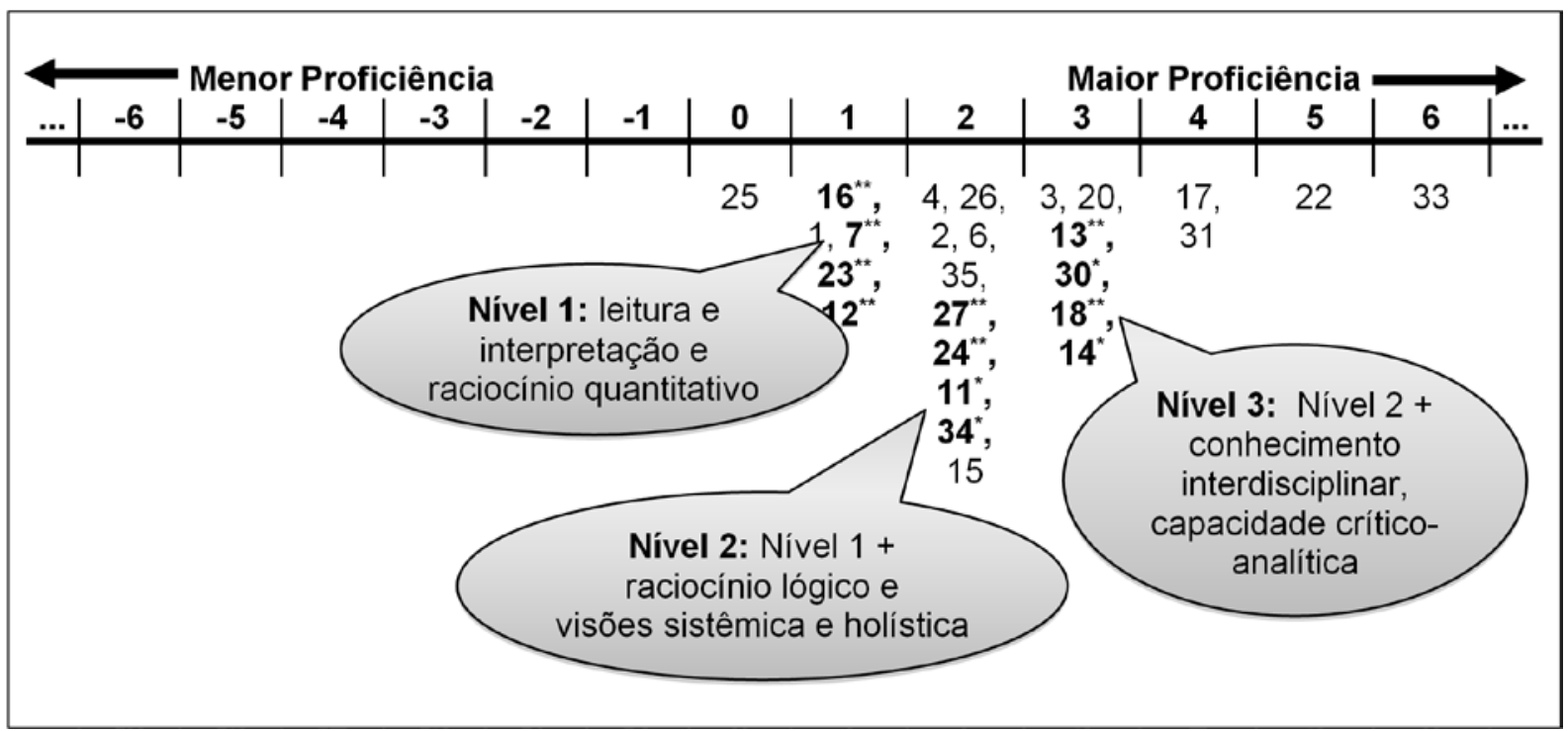

Legenda: * Item "Âncora"; ** Item "Quase âncora".

Fonte: elaborado pelos autores.

Figura 7. Escala de Proficiência (desempenho) da Prova Enade/2012 de Ciências Contábeis 
Os níveis 1, 2 e 3, apresentados na Figura 7, foram definidos conforme os itens "âncora" e "quase âncora", identificados a partir das regras apresentadas na Figura 3. Os conhecimentos e competências sintetizados em cada nível foram identificados de acordo com os conhecimentos e competências exigidos pelas questões que compõem os níveis "âncora" e "quase âncora". Os itens posicionados mais à esquerda da escala, demonstrados na Figura 7, exigiram dos estudantes um menor nível de proficiência. A título de exemplo, a questão 25 da prova requeria dos alunos conhecimentos básicos acerca de terminologias contábeis relacionados à Teoria da Contabilidade e Contabilidade Financeira. Para ter uma alta probabilidade de acertar essa questão, os estudantes deveriam apenas compreender o texto da norma profissional, não sendo exigida capacidade crítico-analítica.

De forma contrária, os itens posicionados mais à direita da escala (Figura 7) exigiram dos estudantes, além do domínio de conhecimentos mais complexos, capacidade crítico-analítica, com visão sistêmica e holística. Por exemplo, a questão 33 demandava do aluno conhecimento interdisciplinar entre Teoria da Contabilidade e Contabilidade Financeira, envolvendo suas aplicações no processo de identificação, reconhecimento, mensuração e evidenciação contábil, além de requerer o domínio de terminologias contábeis, capacidade crítico-analítica, com visão sistêmica e holística para interpretar e aplicar a teoria e normatização inerente à contabilidade. A questão 22 exigia do aluno conhecimento interdisciplinar entre Auditoria Interna e Sistemas de Informação, envolvendo suas aplicações aos controles internos dos subsistemas de estoques e requerendo domínio de terminologias contábeis, capacidade crítico-analítica, com visão sistêmica e holística.

Para resolver a questão 17, o aluno deveria dominar conhecimentos de métodos quantitativos aplicados à Contabilidade que contribuam para geração de informações para o processo decisório, bem como possuir capacidade crítico-analítica para analisar as informações apresentadas. Já a questão 31 demandava conhecimentos interdisciplinares que envolvem a Contabilidade Financeira (Societária) e as Legislações Societária e Tributária. Para resolver a questão, o estudante deveria dominar conhecimentos de Contabilidade Societária, sobretudo, relacionados à identificação do valor da distribuição de lucros aos sócios ou acionistas, em conformidade com critérios societários e em consonância com a legislação tributária referente ao lucro presumido. Nessa questão também era exigido o domínio de terminologias contábeis, interpretação e aplicação da normatização inerente à Contabilidade, capacidade crítico-analítica e visão sistêmica e holística.

Com base nas estimativas mensuradas, foram identificados três níveis de proficiência relacionados à prova Enade/2012. Esses itens estão expostos na Tabela 4. As regras para definição desses itens como itens "âncora" ou "quase âncora" foram apresentadas no tópico 3.3 deste artigo.

Tabela 4

Classificação dos itens por nível da escala

\begin{tabular}{ccl}
\hline \multicolumn{2}{c}{ Painel A: Classificação dos Itens } \\
\hline Nível & Itens & Classificação \\
\hline Nível 1 & $16,7,23$ e 12 & Quase âncora. \\
\hline \multirow{2}{*}{ Nível 2 } & 11 e 34 & Âncora. \\
& 27 e 24 & Quase âncora. \\
& 30 e 14 & Âncora. \\
& 13 e 18 & Quase âncora. \\
\hline
\end{tabular}




\begin{tabular}{cc}
\hline & Painel B: Descrição dos Itens \\
\hline Item & Descrição \\
\hline & Nível 1 \\
\hline
\end{tabular}

Requer o conhecimento da normatização que rege a profissão de auditoria independente no que tange à questão da independência profissional. Envolve descrições de situações que caracterizem possíveis

16 ameaças à independência do auditor. Apesar de exigir o conhecimento de circunstâncias que afetem a independência, requer a compreensão do texto da norma profissional, de modo que não é exigida a capacidade crítico-analítica.

Requer capacidade de leitura e intepretação de textos, de modo que se tenha capacidade de obtenção

7 de conclusões e/ou inferências a partir do uso de indução e/ou dedução. De modo geral, a questão busca identificar se o aluno é capaz de concluir sobre determinado tema a partir de informações implícitas no contexto apresentado.

Envolve cálculos de matemática financeira para cálculo de payback para avaliação da viabilidade de projetos. Tendo em vista que os dados encontram-se representados na forma tabular, não requer habilidades como interpretação e análise crítica do contexto em que a questão é apresentada.

Demanda conhecimento de análise de custos em decisões que envolvem a escolha por compra ou produção de mercadorias. Envolve um procedimento para geração de informações para o processo decisório (de baixa complexidade). Requer o domínio de terminologias contábeis e a utilização de raciocínio quantitativo para identificação e apuração de custos de produção.

\section{Nível 2}

Requer o conhecimento de apuração de custos, especificamente do modelo de custeio por atividades (ABC). Compõe o rol de procedimentos para geração de informações para o processo decisório. Demanda o domínio de terminologias contábeis e a utilização dos raciocínios lógico e quantitativo para solução de problemas com visão sistêmica e holística.

Requer o cálculo de indicadores para análise das demonstrações contábeis mediante a compreensão e conhecimento da terminologia contábil, bem como pelo uso do raciocínio quantitativo. Não exige a interpretação de tais indicadores.

Requer a realização de uma análise Custo-Volume-Lucro (CVL) para identificação de quantidades a serem vendidas por meio da obtenção do ponto de equilíbrio econômico. Consiste em um procedimento auxiliar

27 na geração de informações para o processo decisório. A questão demanda conhecimento de terminologias contábeis e o uso dos raciocínios lógico e quantitativo para solução de problemas com visão sistêmica e holística.

Demanda conhecimento acerca da Demonstração do Valor Adicionado (DVA), especificamente em relação à sua finalidade e à forma como é calculado o valor adicionado. Requer um conhecimento básico acerca de terminologias contábeis.

\section{Nível 3}

Requer conhecimento interdisciplinar entre apuração do resultado contábil e a apuração de tributos mediante a aplicação da legislação tributária para apuração do lucro real. Envolve o domínio de

30 terminologias contábeis, interpretação e aplicação da normatização inerente à contabilidade e capacidade crítico-analítica, com visão sistêmica e holística.

Demanda conhecimento acerca do processo de identificação, reconhecimento, mensuração e evidenciação contábil. Envolve o domínio de terminologias contábeis, interpretação e aplicação da teoria e da

14 normatização contábil, bem como capacidade crítico-analítica para identificação da etapa contextualizada relativa ao ciclo contábil.

Demanda conhecimento de análise CVL para identificação da combinação de produção capaz de maximizar a margem de contribuição da empresa em um contexto que envolve fatores limitantes ao processo

13 produtivo. Consiste em um procedimento para geração de informações para o processo decisório e demanda o domínio de terminologias contábeis e a utilização dos raciocínios lógico e quantitativo para solução de problemas com visão sistêmica e holística.

Demanda o conhecimento e a capacidade de apuração de resultados por meio dos modelos de custeio por absorção e custeio variável. Requer conhecimento acerca de terminologias contábeis. Envolve análise crítico-analítica com visão sistêmica e holística por meio do raciocínio quantitativo para realização de apurações paralelas de custos. 
Como pode ser observado no Painel B, da Tabela 4, estudantes com proficiência situada no Nível 1 são capazes de realizar tarefas relacionadas à leitura e interpretação de textos e normas, cálculos de aritmética e matemática financeira para solução de problemas de baixa complexidade. À medida que passam para o Nível 2, os itens passam a exigir dos estudantes, além do raciocínio quantitativo, também o raciocínio lógico. Complementarmente à leitura e interpretação de textos e normas, nesse nível são necessárias também visões sistêmica e holística relacionadas à geração de informações para o processo decisório.

No Nível 2, é necessário destacar o item 24, sobre a Demonstração do Valor Adicionado (DVA). Apesar de não requerer competências e conhecimentos considerados altamente complexos, o posicionamento do item nesse nível da escala sugere a necessidade de uma maior atenção na estrutura curricular dos cursos. Devido ao recente processo de convergência e por questões curriculares é possível que o estudo dessa demonstração tenha ficado comprometido. Como pode ser observado, esse item foi enquadrado como de média complexidade, porém requer apenas o conhecimento geral da finalidade e dos componentes da DVA, sem maiores exigências, como os casos das demais questões desse nível, que exigiam raciocínio lógico, visões sistêmica e holística.

No Nível 3 (Tabela 4), além do domínio dos conhecimentos e habilidades exigidos nos níveis anteriores como raciocínios quantitativo e lógico e visões sistêmica e holística, os itens desse nível demandam conhecimento interdisciplinar entre os conteúdos contábeis, além de capacidade crítico-analítica. No Nível 3, a leitura e a intepretação de textos e normas são ponto de partida para aplicação prática dos conhecimentos dominados pelo aluno. Conforme esperado, o domínio de conhecimentos, habilidades e competências são cumulativos entre os níveis apresentados. A escala contempla incialmente domínios mais simples, exigindo, conforme o nível aumenta, domínios mais complexos dos estudantes.

Na Tabela 5, são apresentadas as quantidades de estudantes classificados de acordo com os níveis de proficiência estabelecidos na Figura 7.

Tabela 5

\section{Classificação dos estudantes por faixas de proficiência}

\begin{tabular}{|c|c|c|}
\hline Faixas & Quantidade de Estudantes & Frequência \\
\hline Abaixo de 1 & 35.120 & $75 \%$ \\
\hline Nível 1 & 10.169 & $22 \%$ \\
\hline Nível 2 & 1.724 & $4 \%$ \\
\hline Nível 3 & 85 & $0 \%$ \\
\hline Total & 47.098 & $100 \%$ \\
\hline
\end{tabular}

Fonte: elaborado pelos autores.

A partir do estudo da proficiência individualmente apresentada pelos estudantes, os resultados mostram que, de um total de 47.098 estudantes, 35.120 (75\%) ficaram abaixo do Nível 1, ou seja, tiveram proficiência representada pelo $\theta$ da TRI inferior à primeira faixa (Nível 1) da escala de proficiência (Figura 7), o que significa que a maior parte dos estudantes não é capaz sequer de dominar os conhecimentos e competências mínimos exigidos no exame; 10.169 (22\%) estudantes têm proficiência no Nível 1; somente 1.724 estudantes (1\%) estão no Nível 2, e apenas 85 estudantes dominam os conhecimentos exigidos no Nível 3.

Similarmente aos estudos de Scher et al. (2014), Coelho et al. (2014) e Primi et al. (2011), houve viabilidade da aplicação da TRI na prova de Contabilidade do Enade. De maneira específica, assim como realizado por Primi et al. (2011), foi possível estabelecer faixas de desempenho nas quais foram segregados os tipos de conhecimentos, habilidades e competências exigidas para os estudantes se enquadrarem em cada faixa. 


\section{Conclusão e Sugestões para Futuras Pesquisas}

Este estudo teve como objetivo mensurar o desempenho (proficiência) dos estudantes de Ciências Contábeis no Enade, por meio da TRI. A partir da estimação realizada com o ML3P, decorrente da TRI, foi realizada a mensuração da proficiência dos estudantes de Ciências Contábeis que fizeram a prova Enade/2012 e criada uma escala de medida padronizada.

A análise dos itens (questões) evidenciou a capacidade da prova em mensurar a proficiência dos estudantes nos diferentes níveis de domínio cognitivo exigido pelo exame. Nesse contexto, a TRI demonstrou capacidade de capturar a distribuição da proficiência dos estudantes de Ciências Contábeis ao longo dos níveis exigidos pela prova.

Os resultados da pesquisa apontaram que os itens contidos na prova do Enade representam um alto grau de dificuldade para o grupo que realizou a prova. Tanto na análise regional ou com base em outras características (por exemplo, escolaridade dos pais, tempo de dedicação aos estudos ou cursar a graduação em IES pública ou privada), constatou-se que a proficiência dos estudantes tende a ser baixa, isto é, abaixo de 0 , considerando a escala 0,1 .

A maioria dos estudantes que realizou a prova não apresentou nem o domínio cognitivo compreendido pelo Nível 1 da escala. Este resultado corrobora o baixo desempenho dos estudantes apontado pelo relatório do Inep (2014) para esta prova e aponta, especificamente, em quais aspectos e conhecimentos podem ser encontradas fragilidades de aprendizagem. Infelizmente, esse desempenho negativo também foi observado na área de ciências contábeis em provas anteriores (Santos, 2012). Uma vez que tais avaliações têm o intuito de acompanhar a situação da educação ofertada pelos cursos de graduação aos estudantes, é relevante que ações sejam tomadas envolvendo políticas públicas para que essa situação seja revertida. Neste caso, cabe investigar se a causa do grau de dificuldade dos itens que compõem o instrumento está relacionado à complexidade das questões ou à ineficiência da aplicação dos recursos educacionais e das políticas públicas adotadas nas IES, tornando o processo de ensino-aprendizagem insatisfatório.

Vale ainda destacar que, enquanto estudos realizados com base na TCT abordam a questão do desempenho de maneira agregada, a análise pela TRI permitiu a identificação pontual dos conhecimentos, capacidades e habilidades exigidas em cada nível da escala. Ao desmembrar a proficiência em níveis, evidenciando os conhecimentos exigidos, é possível uma atuação pontual de professores, IES e respectivas autoridades nas questões específicas em que foram demonstradas deficiências na aprendizagem.

Dados os benefícios mencionados e apresentados pela TRI neste estudo, pesquisas posteriores, relacionadas a determinantes do desempenho de alunos em Ciências Contábeis poderiam adotar como base para mensuração do desempenho dos estudantes as medidas fornecidas por modelos baseados na TRI. Essa análise possibilitaria estudar determinantes baseados em diferentes níveis de proficiência, contribuindo para o avanço nos estudos relacionados a esta área.

\section{Referências}

Andrade, D. F., Tavares, H. R., \& Valle, R. C. (2000). Teoria da Resposta ao Item: conceitos e aplicações. São Paulo: Associação Brasileira de Estatística (ABE).

Bartlett, S., Peel, M. J., \& Pendlebury, M. (1993). From fresher to finalist: a three year analysis of student performance on an accounting degree programme. Accounting Education, 2(2), pp. 111. http:// dx.doi.org/10.1080/09639289300000013

Becker, G. S. (1962). Investment in human capital: A theoretical analysis. The journal of political economy, 70(5), pp. 9-49. http://dx.doi.org/10.1086/258724

Birnbaum, A. (1968). Some Latent Trait Models and Their Use in Infering an Examinee's Ability. In Lord, F.M., \& Novick, M.R. (Ed.) Statistical Theories of Mental Test Scores. Reading, MA: Addison-Wesley. 
Blaug, M. (1992). The methodology of economics: Or, how economists explain. Cambridge University Press.

Bock, R. D. (1997). A brief history of Item Response Theory. Educational Measurement: Issues and Practice, 16(4), pp. 21-33. http://dx.doi.org/10.1111/j.1745-3992.1997.tb00605.x

Boomsma, A., Van Duijn, M. A. J., \& Snijders, T. A. B. (2000). Essays on item response theory. Lecture Notes in Statistics (Springer-Verlag), pp. 157. New York: Springer.

Byrne, M., \& Flood, B. (2008). Examining the relationships among background variables and academic performance of first year accounting students at an Irish University. Journal of Accounting Education, 26(4), pp. 202-212. http://dx.doi.org/10.1016/j.jaccedu.2009.02.001

Clinton, B. D., \& Kohlmeyer, J. M. (2005). The effects of group quizzes on performance and motivation to learn: Two experiments in cooperative learning. Journal of Accounting Education, 23(2), pp. 96 116. http://dx.doi.org/10.1016/j.jaccedu.2005.06.001

Coelho, E. C., Ribeiro Junior, P. J. \& Bonat, W. H. (2014). Exame nacional de desenvolvimento de estudantes de estatística-desafios e perspectivas pela TRI. Revista da Estatística da Universidade Federal de Ouro Preto, 3(2), pp. 323-337.

Cruz, A. J., Nossa, V., Balassiano, M., \& Teixeira, A. (2013). Desempenho dos Alunos no Enade de 2009: um estudo empírico a partir do conteúdo curricular dos cursos de Ciências Contábeis no Brasil. Advances in Scientific and Applied Accounting, 6(2), pp. 178-203. http://dx.doi.org/10.14392/ asaa.2013060203

Cunha, J.V.A., Cornachione Junior, E.B. \& Martins, G.A. (2010, Mai./Jun.). Doutores em Ciências Contábeis: Análise sob a Óptica da Teoria do Capital Humano. RAC, Curitiba, 14(3), pp. 532-557. http:// dx.doi.org/10.1590/s1415-65552010000300009

Davidson, R. A. (2003). Relationship of study approach and exam performance. Journal of Accounting Education, 20(1), pp. 29-44. http://dx.doi.org/10.1016/s0748-5751(01)00025-2

Edelen, M. O. \& Reeve, B. B. (2007). Applying item response theory (IRT) modeling to questionnaire development, evaluation, and refinement. Quality of Life Research, 16(1), pp. 5-18. http://dx.doi. org/10.1007/s11136-007-9198-0

Hanushek, E. A. (1979). Conceptual and empirical issues in the estimation of educational production functions. Journal of human Resources, 14(3), pp. 351-388. http://dx.doi.org/10.2307/145575

Instituto Nacional de Estudos e Pesquisas Educacionais Anísio Teixeira - INEP. (2014). Relatório de Síntese, Ciências Contábeis - ENADE 2012. Recuperado de http://portal.inep.gov.br/web/guest/enade/ relatorio-sintese-2012.

Lopes, F. L. \& Vendramini, C. M. M. (2015). Propriedades psicométricas das provas de pedagogia do ENADE via TRI. Avaliação: Revista da Avaliação da Educação Superior, 20(1), pp. 27-47.

Lord, F. M. (1952). A theory of test scores (No. 7). Psychometric Monograph.

Miranda, G. J. (2011). Relações entre as qualificações do professor e o desempenho discente nos cursos de graduação em contabilidade no Brasil. Tese de Doutorado em Controladoria e Contabilidade, Faculdade de Economia, Administração e Contabilidade (USP), São Paulo, SP, Brasil. Recuperado de http://www.teses.usp.br/teses/disponiveis/12/12136/tde-16032012-190355/pt-br.php.

Moreira, F. J., Jr (2010). Aplicações da teoria da resposta ao item (TRI) no Brasil. Rev. Bras. Biom, 28(4), pp. 137-170.

Primi, R., Hutz, C. S. \& Silva, M. C. R. (2011). A prova do ENADE de psicologia 2006: concepção, construção e análise psicométrica da prova. Avaliação Psicológica, 10(3), pp. 271-294.

R Development Core Team. (2012). R: A Language and Environment for Statistical Computing. R Foun-dation for Statistical Computing, Vienna, Austria. 
Rasch, G. (1960). Probabilistic Models for Some Intelligence and Attainment Tests. Copenhagen: Danish Institute for Educational Research.

Rasera, J. B. (1999). Léconomie de l'éducation et la question du développement. In: Paul, J.-J. (Ed.) Administrer, gérer, évaluer les systèmes éducatifs. Paris: ESF.

Samejima, F. (1969). Estimation of latent ability using a response pattern of graded scores. Psychometrika monograph supplement.

Santos, N. A. (2012). Determinantes do desempenho acadêmico dos alunos dos cursos de ciências contábeis. Tese de Doutorado em Controladoria e Contabilidade, Faculdade de Economia, Administração e Contabilidade (USP), São Paulo, SP, Brasil. Recuperado de http://www.teses.usp.br/teses/disponiveis/12/12136/tde-11062012-164530/en.php.

Santos, N. D. A., Cunha, J. V. A. D., \& Cornachione Junior., E. B. (2009). Análise do Desempenho dos Cursos de Ciências Contábeis do Estado de Minas Gerais no ENADE/2006. Anais do Congresso da Associação Nacional dos Programas de Pós Graduação em Ciências Contábeis - ANPCONT, IAAER-ANPCONT, São Paulo, SP, Brasil, 3.

Scher, V. T., Moreira, F. J., Jr., Correa, A. C., Schuch Junior, V. F., Andrade, D. F., \& Bortolotti, S. L. V. (2014). Uma aplicação da teoria da resposta ao item na avaliação do ENADE do Curso de Administração. Anais do XIV Colóquio Internacional de Gestão Universitária - CIGU, Florianópolis, SC, Brasil, 14.

Schultz, T. W. (1960). Capital formation by education. The journal of political economy, 68(6), pp. 571-583.

Souza, E. S. (2008). ENADE 2006: Determinantes do Desempenho dos Cursos de Ciências Contábeis. Dissertação de Mestrado em Ciências Contábeis, Programa Multiinstitucional e Inter-Regional de PósGraduação em Ciências Contábeis, Universidade de Brasília/UFPB/UFRN, Brasília, DF, Brasil. Recuperado de http://repositorio.unb.br/handle/ 10482/3949.

Van Der Linden, W. J. \& Hambleton, R. K. (1997). Handbook of Modern Item Response Theory. New York: Spring-Verlag.

Waltenberg, F. D. (2006, jan./abr.) Teorias econômicas de oferta de educação: evolução histórica, estado atual e perspectivas. Educação e Pesquisa, 32(1), pp. 117-136. http://dx.doi.org/10.1590/s151797022006000100008

Wright, B. D. (1968, February, 11-13). Sample-free Test Calibration and Person Measurement. Paper Presented At The National Seminar On Adult Education Research (Chicago). 